\title{
Trust Based Contracting in Virtual Organizations:
}

A Concept Based on Contract Workflow Management Systems

\author{
Lenz K.* , Oberweis A.*, Schneider S.** \\ *Institute of Information Systems * ** IBM Germany \\ University of Frankfurt/Main Frankfurt/Main
}

\begin{abstract}
For participants in virtual organizations it is necessary to work together on a temporary basis in order to solve specific problems. Both the search for adequate partners and the organizational set-up have to be very fast and efficient. The main difficulty of building a cooperation lies in finding the right balance between time-consuming, but safe ways based on traditional contracts, and less reliable, but faster ways based solely on traditional forms of trust. This paper introduces a contract/trust based solution and describes a computersupported negotiation process to make the process of creating a virtual organization fast and safe at the same time. We propose an interorganizational workflow based on a combination of a minimal set of contractual documents supplemented by trust-based features. The workflow enables partners to establish a temporary cooperation agreement within a relatively short time. As workflow modelling language we have chosen so-called XML-nets, a novel variant of high level Petri nets which combines interorganizational workflow models with XML-document descriptions.
\end{abstract}

\section{INTRODUCTION AND MOTIVATION}

Virtual organizations consist of independent companies which use electronic networks, especially the internet, for a temporary cooperation [HaB97]. In the initial phase the companies interested in setting up a virtual organizations start looking for potential partners with complementary characteristics in their interaction with the client. The companies cooperate on a short-term basis to solve specific problems; once the problems are solved, the cooperation ends. In the era of the internet cooperation agreements must be established within an extremely short period of time in order to be able to successfully compete with rivals [SaV99]. Since the traditional ways of coming up with cooperation agreements are usually very time- and 
resource-consuming and since laws do not change as fast as technology does, a type of cooperation that is based on a trust model, might be an efficient alternative. This model (see for example [Lew99, MiF98]) does not rely on contracts but instead builds virtual organizations based only on trust-oriented partnerships. Even though trust-oriented relationships can be seen as relatively risky [Luh88] for all parties involved (especially because they might lead to opportunistic behaviour) they still provide clear competitive advantages and serve as a substitute for traditional hierarchical governance [KaJ99]. Yet, virtual organizations carry one important disadvantage: the conflict between the secure, but slow preparation mode of traditional cooperation agreements and the fast, but risky trust-based model of cooperation. This raises two basic questions which will be discussed in the following:

a) If a virtual organization needs a contract, how can the creation of this contract be speeded up?

b) If mutual trust helps to speed up the contracting process, how can

potential/future members of virtual organizations develop and increase mutual trust?

"A contract is a promise or a set of promises for the breach of which the law gives a remedy, or the performance of which the law in some way recognizes as a duty." [Mac74, p.693]. We have already referred to the fact that virtual organizations present themselves as one single organizational unit when interacting with clients. For sales purposes, only one of the participants of a trust-based virtual organization directly interacts with the client. Since these relationships with the client are fixed in written contracts, the client interface of the virtual organization is the party that carries all business risks. All other relationships between the parties involved in the virtual organization are trust-based relationships and thus not contract-based. This means that the client interface is the only party who is liable for all delivered products and services towards the client, even for those delivered by other members of the virtual organization.

Contract management can be divided into several phases: planning and designing contracts, negotiation, conclusion and contract controlling [Ert99]. Because of their particular importance for virtual organizations, we focus on the negotiation and conclusion phases. Separating similar contracting problems, so called different levels of negotiation (Figure 1), will help to speed up and automate the process by bundling units of similar problems to find cooperation agreements.

In a first instance, intelligent software agents manage basic assumptions which are essential and the participants do not want further debates on. This kind of negotiation is relatively static but one of the fastest ways to find first agreements. For the discussion of more detailed questions during the next stage the partners have to use specific negotiation tools such as contract workflow management systems and other groupware tools like e-mail, video conferencing, etc. 


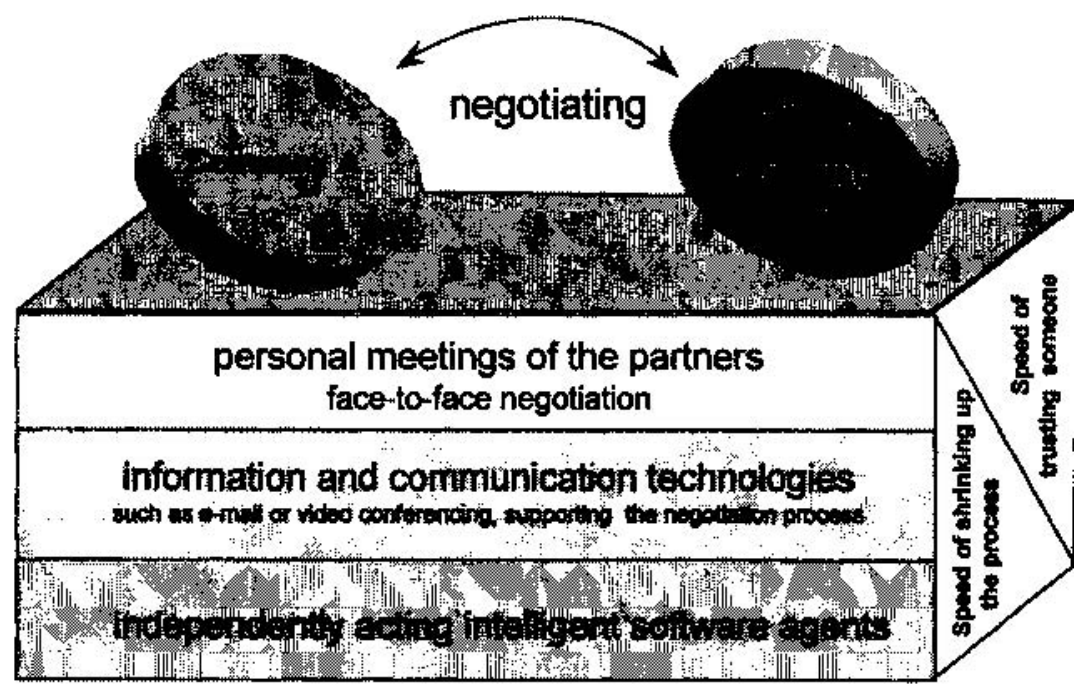

Figure 1: Negotiation Levels

One possible contract workflow will be described in the following sections of this paper. In a third instance, the partners have to discuss more complex topics in face-to-face meetings, which are more effective for building mutual trust, but at the same time are relatively expensive.

The model also uses software agents which are more efficient in matching basic assumptions, but are not able to cope with the process of establishing a trust-based relationship. In the following we concentrate on the issue of building mutual trust in virtual organizations, that is trust between the involved people. The three-step model presented in Figure 1 is meant to save time and to speed up the entire process by preventing time-consuming discussions. Furthermore, it allows for a more focused process since the partners have to be familiar with all the clearly structured steps towards agreement.

\section{ELECTRONIC SUPPORT OF THE CONTRACTING PROCESS}

"The term contracting is used to describe efforts by individuals to assign or to modify property rights. In this context, contracting includes bargaining among private claimants within groups..." [Lib89, p.4].

An overview of software agents to support contracting (in particular negotiating the first instance of the negotiation model) in electronic markets can be found in the WWW under URL http://www.agents.media.mit.edu/ groups/agents/publications/. In the following we focus on the second level, i.e. information and communication technologies to support the negotiation process, and especially on contract workflow management systems to support and speed up the process of writing up contractual agreements [HeW00] (compare also the COSMOS architecture under http://vsyswww.informatik.uni-hamburg.de and the project CrossFlow under 
http://www.crossflow.org). We analyze these contractual processes as a basis for developing contract workflow management systems. By using contract workflows different people in the companies involved can easily exchange documents.

Since so-called XML-nets [LeO01] allow the integration of electronic document exchange and interorganizational processes, they will be used to describe the process of finding agreements in a virtual organization. XML-nets support the exchange of documents which is represented by models of interorganizational business processes based on a novel variant of high-level Petri nets [Gen87, ObS96] and on XML (eXtensible Markup Language) [W3C00]. XML is a document declaration standard proposed by the World Wide Web Consortium (W3C, http://www.w3.org/). A socalled document type definition (DTD) describes the structure of valid XML documents of a certain type.

Petri nets are a formal graphical process description language which allows for the computer-supported analysis and validation of business processes [DeE00]. They consist of static components (the places, depicted by circles) and dynamic components (the transitions, depicted by rectangles) that are connected by directed arcs. Low-level Petri nets [Pet81] are well suited for the initial modeling of a complex workflow whereas high-level Petri nets like predicate/transition nets [Gen87] integrate behavior- and object-related aspects of workflows.

In XML-nets, the places are interpreted as containers for XML documents. The transitions and the corresponding descriptions of the document manipulation (i.e. the labels of the adjacent edges and the transition inscriptions) determine the flow of the documents. The Graphical XML Schema Definition Language (GXSL) ist used to model for each place in the net the structure of the respective valid XML documents. The GXSL based manipulation language XManiLa is used to model system dynamics [LeO01]. Due to the formal notation, well known analyzing methods and discrete simulation can be applied to XML-nets. Furthermore XML-nets can be directly interpreted by a respective workflow engine.

\subsection{Process View: The Process of Contractual Agreements}

As already mentioned, there are different phases in the process of setting up a cooperation between two organizations. The following scenario takes place after the potential partners have found each other and then have to negotiate their cooperation agreement (Figure 2). In this case, for example, company A creates an information document containing the issues of the project which the mutual software agents already agreed on and those which are still unclear. 


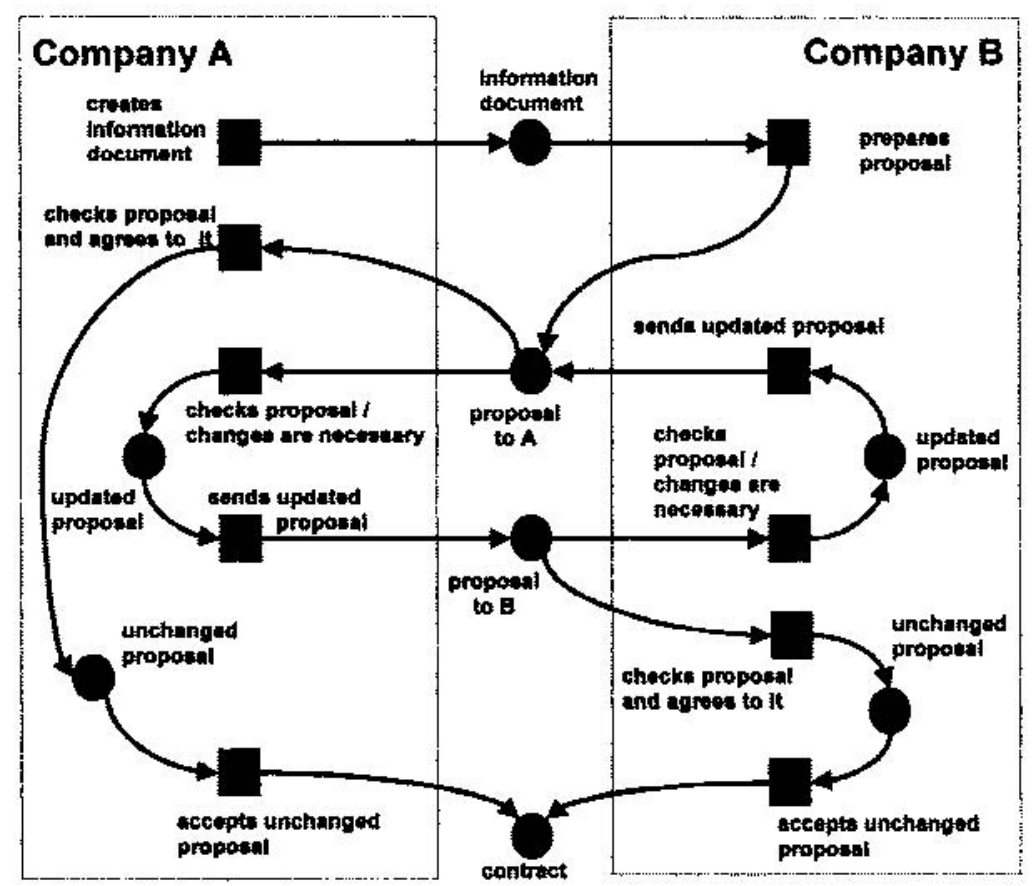

Figure 2: Complex Negotiation Process

If company $\mathrm{B}$ is able to deliver or produce the missing items it can fill in or change the relevant paragraphs and prepare a proposal document. This proposal document will be sent back to company A. In a simple case of contractual agreement company A will accept the proposal as it is; then a contract is closed. These issues are also discussed in the literature under the keyword e-contracting [GSS00]. Often the first proposal made by company B has to be changed, and company A then sends a new proposal to company $\mathrm{B}$. The companies will iteratively exchange proposals until one proposal will be agreed upon in its entirety. This results in the following process: company A creates an information document describing the partnership in an organizational as well as a technical way. Company B prepares a proposal based on this information and sends it back to company A. Now company A has to check the proposal and either agrees to it and accepts it, which means that the contract is closed, or -which is more likely- that the companies have to re-negotiate their respective output of goods and services.

\subsection{Document View: Document Structure of Contracts}

The Petri net in Figure 2 describes the negotiation behavior of the two companies. Until now, the specification of the documents' structure is still missing. In order to describe the document flow of the negotiation process in detail we have to add information to the Petri net and thereby extend it to an XML-net. For each 
place of the Petri net, the respective type of documents has to be described by a graphical XML schema. XManiLA is then used for specifying the document manipulation by extended graphical XML schemas which label the edges in an $\mathrm{XML}$ net $^{1}$ [LeO01].

In the given process three main documents are necessary: an information document, a proposal document, and a contract document. The information document (Figure 3) provides general information about the planned virtual organization (planned_cooperation) including the initiator, the background information and a description of the solution. Additionally, it contains the timeframe (duration) and the work which has to be done by the parties involved (piece_of_work). The piece_of_work element also describes the interfaces with all other related work products.

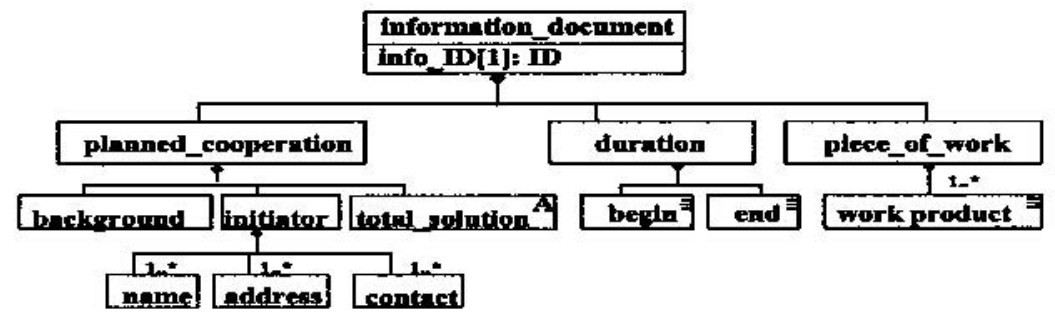

Figure 3: Graphical XML Schema for the Information Document

Once the information document has been received by company $\mathrm{B}$, and if company B is interested in the suggested form of cooperation, the document will be transformed into a proposal. In addition to the information document, the proposal contains data about the partners, commercial business and legal terms, pieces of work which have to be achieved, and clearly defined hallmarks for the project planning process and arrangements about the cooperation.

The contract document (Figure 4) is similar to the proposal. In addition to the content of the proposal the sender expresses his intention to close the contract.

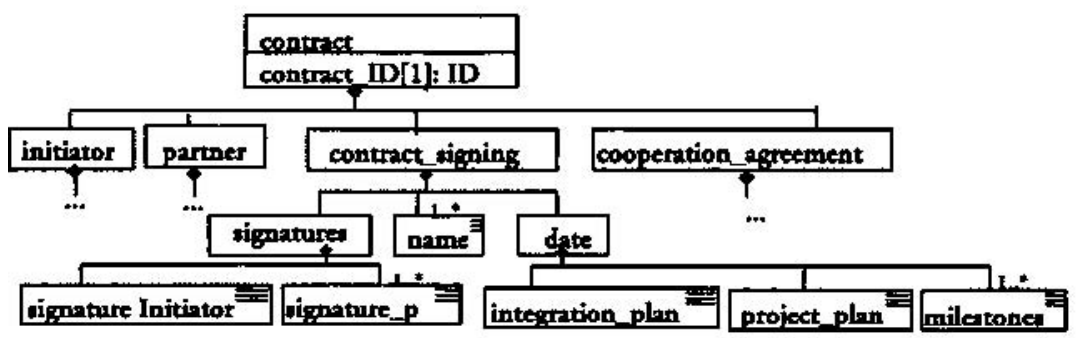

Figure 4: Graphical XML Schema for the Contract Document

1 Due to place limitations we cannot give a detailed introduction into XML-nets here. For further information concerning XML-Nets see, e.g., http://lwi2.wiwi.uni-frankfurt.de/ projekte/xmlnet/default.htm. 
The difference between a proposal and a contract is that both partners sign it, which proves their willingness to cooperate with each other (contract_signing). The cooperation contract describes the rights and duties of the partners. Enclosed are thus statements of contract partners (contract_partner), the commitments of the partners and legal aspects (cooperation_agreement).

We can now assign the schemas to the corresponding places of the Petri net in Figure 2, for example the GXS in-formation_document to the place 'document of information', the GXS proposal to the places 'proposal to A' and 'proposal to B' etc. Moreover the graphical XML schemas for the information document, the proposal and the contract serve as a basis for describing the manipulation of the documents during the negotiation process: From the GXS we can derive the extended GXSs, that describe insertion, deletion and manipulation operations on information documents, proposals, or contracts respectively. These operations are carried out whenever a transition occurs (i.e. whenever the event of operations on the documents takes place). The extended GXSs that we have assigned to the edges of the Petri net thereby exactly specify the documents that are manipulated by the occurring transition and the way these documents are manipulated. An excerpt of the resulting XML-net can be seen in Figure 5.

The graphical XML schemas information_document and proposal describe the documents contained in the places "information document" and "proposal to A". The extended schemas serve as edge labels for specifying the operations on these documents for the transition "prepares proposal". The black bar on the left side of the root element indicates that an information document is deleted and a new proposal document is created. Moreover, the usage of variables allows for ensuring equality of elements between the deleted and created document. 


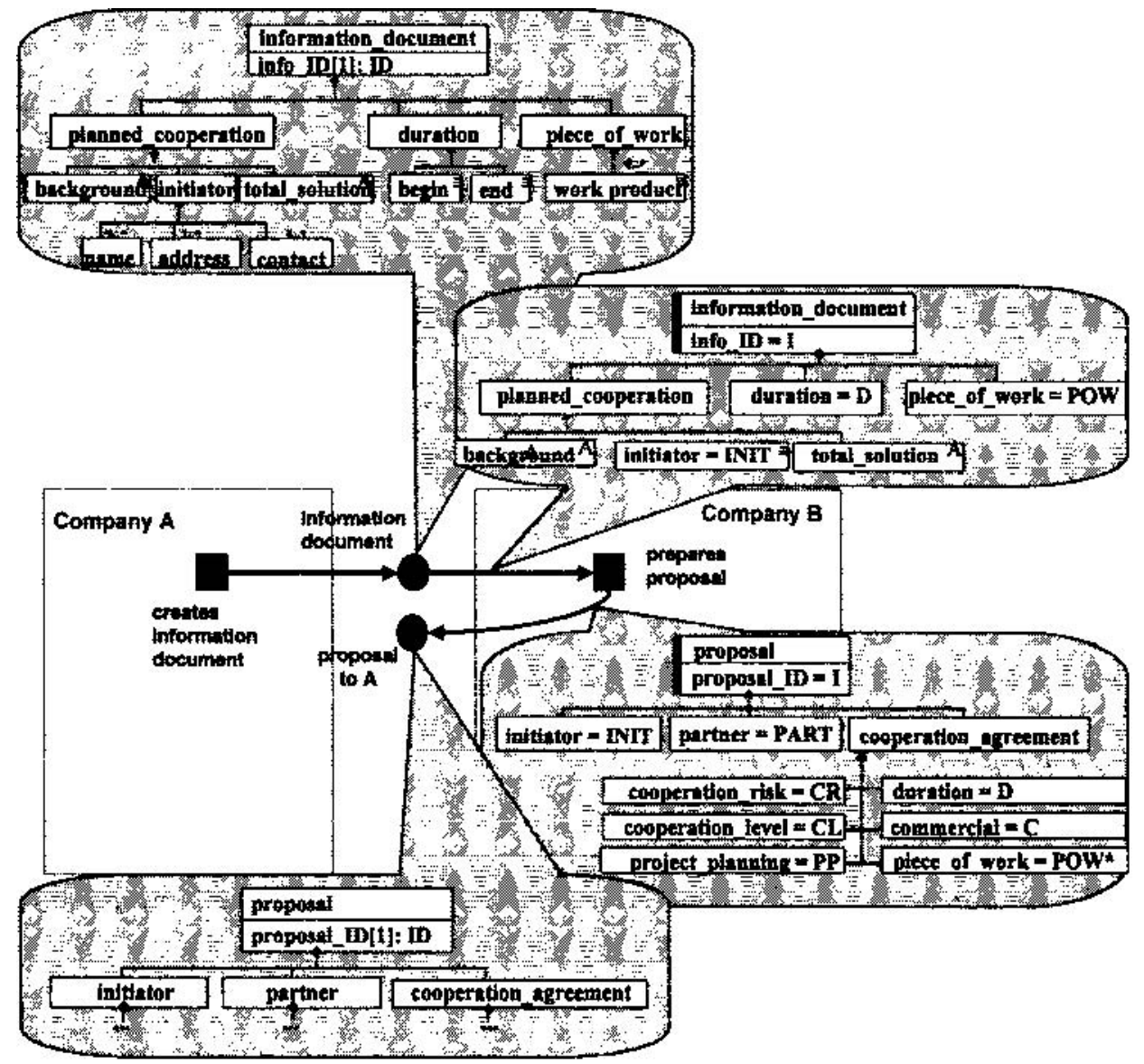

Figure 5: XML-net Excerpt of the Process

\section{ACCELERATING THE PROCESS OF DEVELOPING TRUST}

In virtual organizations trust needs to be managed [Zuc86]. This means that mechanisms for establishing and accelerating trust online and for preserving trust need to be introduced. Ishaya/Macaulay describe influencing mechanisms of the process of developing trust [IsM00] which leads to the following three patterns of mutual trust:

1. Swift trust (trust by pressure ${ }^{2}$ ): If there is only a short window of opportunity for a product or service and if the involved companies only have a very limited time frame available for working together and if there is only a minimal amount of shared objectives companies simply need to mutually assume their partners

2 See also www.ascusc.org/jcmc/vol3/issue4/jarvenpaa.html. 
trustworthiness [MWK96]. In this case a self-fulfilling prophecy will lead to mutual trust. But this is a risky operation. We also call this phenomenon virtual trust, because in the initial phase the partners act as if they were actually trusting each other.

2. Incremental trust: In this case an actual exchange of purchased goods and services (trusted actions) leads to mutual trust. Both parties provide trusted actions and compare the results with their expectations based on their own preceding actions. The process of trust management is modeled by a place/transition net [Pet81] with infinite place capacity (Figure 6). The number of tokens in the place "mutual trust counter" increases with the number of trusted actions. Each company can set its own threshold for trusting the partner (e.g. company A five trust points).

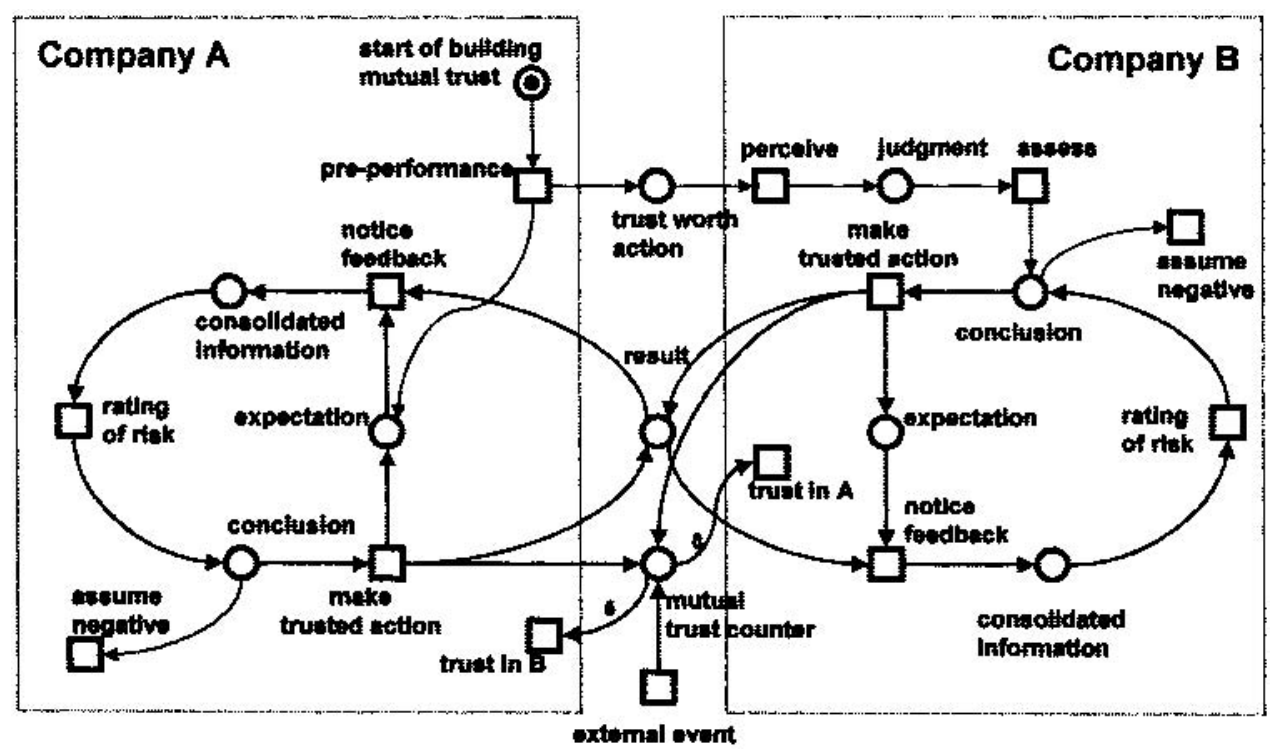

Figure 6: Petri Net for the Trust Management Process

Let us assume that company A executes a pre-performed trustworthy action and hands it over to company $\mathrm{B}$. The evaluation carried out by company $\mathrm{B}$ leads to the conclusion that company $\mathrm{B}$ either decides to give the proposal a negative evaluation or to perform a trusted action as well. Company A receives the feedback, confirms the information, and uses it to compare the chances and risks of trusting company $\mathrm{B}$.

Afterwards company A may either come to the conclusion that it is safe to perform another trusted action or it may seem more appropriate not to trust company $\mathrm{B}$ due to negative assumptions. If company A performs another trustworthy action company B will do the same. The more loops are made, the more trust there will be between the companies, and the faster the process of information exchange is, the faster mutual trust will increase. If there are more than two parties involved, there are further possibilities for building trust such as certificates issued by a (neutral) 
third party (see for example http://www.truste.com). Here we refer to social or relational trust, not to trust in the sense of technical mechanisms or certifications as for instance in the case of SSL. Trust can also be built up through reputation based on public opinion [SWZ99]. In this case computer systems collect, distribute and aggregate comments and collect past behavior of the participating organizations [Shn00]. Trust can also be measured with the help of a calculation system based on rewards and punishment. Therefore we integrate a mutual trust counter for gathering points of trustworthiness or the stage of reputation of the involved companies. Furthermore external events can influence these counters in case of increasing shares for example.

3. Historical trust: This form of building mutual trust by prediction requires partners who have personally known each other over a long period of time and have common shared values. This is a more familiar model and traditional way of emerging mutual trust which is obviously not suitable for virtual organizations.

Constructing trust in virtual organizations is difficult because of the anonymous character of the internet and the time pressure all participants are faced with. Thus a combination of incremental trust and swift trust can be used to speed up the process of contracting in virtual organizations and it can even become a part of or complement of the contract process to speed it up.

\section{TRUST AS A PARTIAL SUBSTITUTE OF CONTRACTS}

The concept described below is based on the idea that elements of trust can be used as a partial substitute for contracts to save negotiation time. In this case trust can replace parts of the negotiating process and of the negotiating documents. When you trust someone you don't have to use all the paragraphs (suggested) of reducing risks only the one which are elementary based on the level you trust on. Trust is seen as an accepted instance of vulnerability to another party's possible interference with one's own sphere [FKH00], which makes purchases of goods and services a more risky venture and gives partners the possibility to opportunistic behavior. Building mutual trust in cyberspace depends on media richness [DLT87] and the social presence theory [SWC76]. This means that the more frequent the use of media during negotiation and the closer the resemblance of communications over the internet looks like a face-to-face conversation, the quicker mutual trust will increase. Thus the following requirements on contract workflow management systems are to be fulfilled:

1. It is necessary to work with different types of using common (internet) standards to accelerate the cycles of trust management. Using a variety of information and 
communication technologies can help to speed up the process of building mutual trust (trust view).

2. It is also necessary to use supporting document and communication standards such as XML and TCP/IP to make it technically feasible for different organizations to be easily linked with each other (technical view).

3. It is necessary to use an interorganizational, well structured and well known process to make the agreements more transparent and comprehensible for the involved partners by using the negotiation model which helps to speed up these processes (contractual view).

In Figure 5 a combination of the contract and trust process is presented. For that purpose we combine the XML-net of the negotiation process (filled places and transitions) and the trust management process of Figure 7 (unfilled places and transitions) to a hybrid Petri net. The two nets are merged by overlapping transitions (merging transitions).

Let us assume that company A plans a virtual organization and starts by evaluating the risks that are associated with this project, e.g. the question of passing on important information to a third party. These evaluations are then used as the basis for preparing a document which contains the basic principles of the cooperation. These documents of principles also include the information document described before. When sending this document to company B, company A performs a trusted action. This trusted action can be seen as a progress on services, products or know how. The document that has been transmitted represents a contractual framework which provides a basic set of intentions and contains suggested general agreements about the cooperation, whereas in a traditional contract all agreements would have to be fixed in detail. For this framework the same document structure can be used; however, several paragraphs are intentionally left open. Company B evaluates the document, and after assessment it sends the framework back to company A which implies a trusted action. Until now a contract does not exist but instead only a document of understanding is available. While interacting the partners agree on basic assumptions and commitments which are the basis for a quick cooperation and - what is even more important - enables them to start working together right away.

In case of modifications, company B updates the framework and sends it back, together with a trusted action. Company A confirms the information and reevaluates the risk of the cooperation. After that, company A either agrees on the framework (for that a certain numbers of trust points are a precondition for contracting and this may be different for both companies) or claims more updates on the framework. In this case the updates and trusted actions are sent to company B. Company B confirms the information and evaluates its own risks, too, before either agreeing or suggesting additional updates. If company $\mathrm{A}$ and $\mathrm{B}$ agree to the framework a minimal common ground exists which can then be complemented and put together with trusted actions into a cycle of trust-based relationship based on 
contracts. These cycles differ in the trust actions and negotiations involved. The benefit of this cycle-based proceeding is that it allows for the cooperation to start right away without a negotiated contract and without a partnership based only on trust. In the next cycle the partners agree on more detailed specific business needs as well as on shared values for the virtual organization.

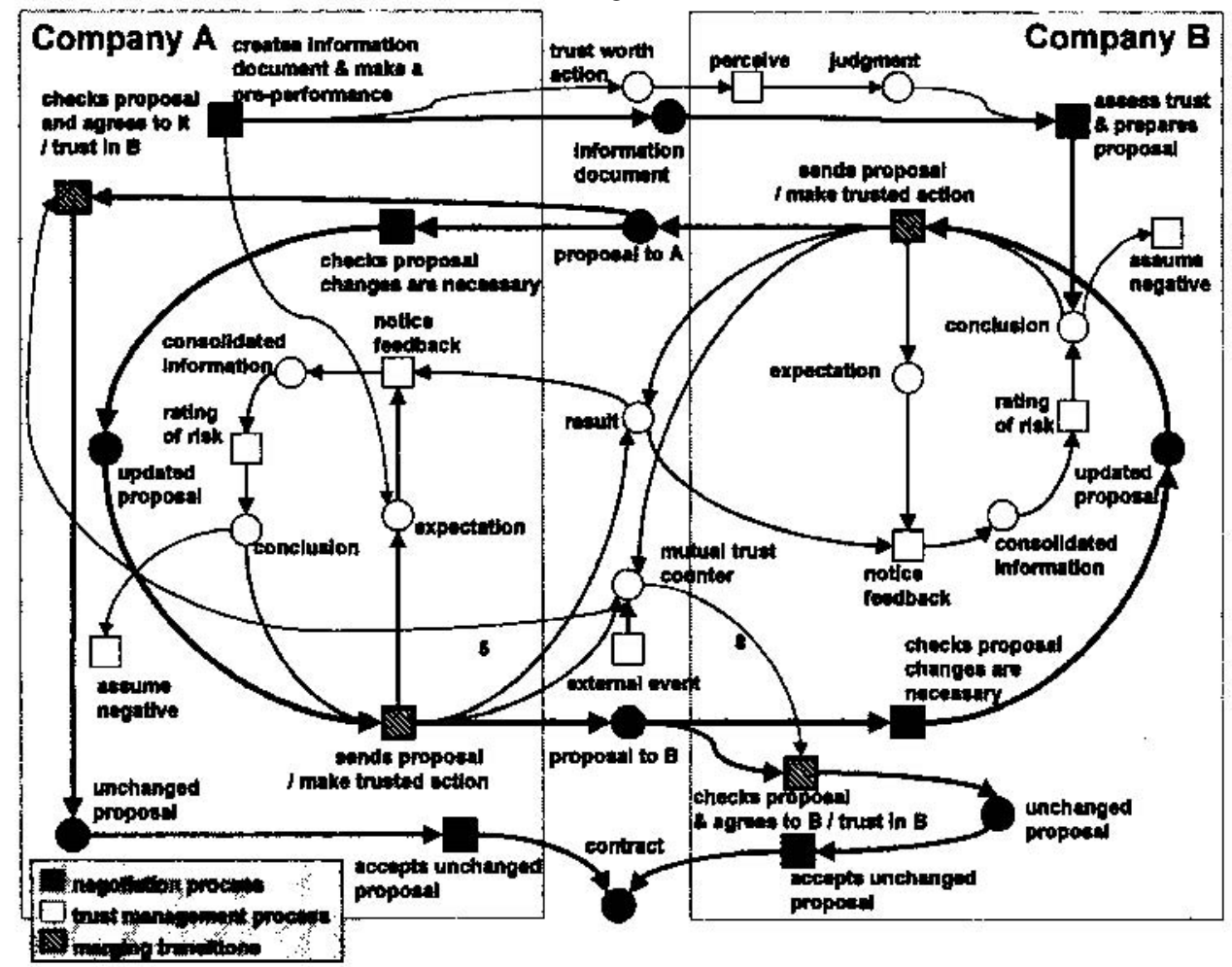

Figure 7: Petri Net of the Contract-Trust Process

Later the partners can manage cooperation with the help of trust rating models based on reputation, etc. There are models possible based on other hedging mechanisms which can be organized in an open form with no central instance (on the web), or they can be hosted by an independent third party. Whenever a virtual organization ends the partners evaluate each other according to negotiation habits, reliability, flexibility etc. Thus, companies accumulate so-called trust points, according to which they are classified into different risk classes. These classes correspond to categories of contractual paragraphs the companies use in the first phase of the contractual-trust- model. The number of trust points correlates with the number of necessary contractual agreements: the more trust points the higher the reputation and the lower the number of paragraphs and vice versa. 


\section{CONCLUSION}

Building virtual organizations without contracts is a risky venture especially for the organization client interface. In this paper, we proposed a negotiation model that allows for accelerating the process of finding a cooperation agreement based on a contract. Building mutual trust is one of the main elements in this model. To make contract workflow management systems feasible, XML-nets are used which integrate the structure as well as the flow of the relevant documents. The main advantage for virtual organizations is that this model allows for an early start of the cooperation, even when the partners are still working on their agreements with the help of "documents of understanding" and "trusted actions", and finally leads to a negotiated contract.

XML-nets and additional trust rating models with the help of mutually treated trust counters are proposed for the specification on a contract workflow management system supporting virtual organizations. Further work of the project VirtO (http://lwi2.wiwi.uni-frankfurt.de/projekte/virto/ default.htm) at the University of Frankfurt aims at providing a detailed description and integration of trust building models (based on ratings, reputations, trusted actions, etc.) into the XML-nets. Currently we are developing a simple prototype simulator for XML-nets based on a native XML database system. We plan to use this simulator for the evaluation of our trust-contract process in addition to the application of analysis methods (like for example reachability analysis). We also plan to introduce integrity rules into XMLnets in order to specify requirements concerning the trust management process in a declarative way.

\section{REFERENCES}

[DeE00] Desel, J.; Erwin, T.: Modeling, Simulation and Analysis of Business Process; in: van der Aalst, W.; Desel, J.; Oberweis, A. (eds.), Business Process Management - Models, Techniques and Empirical Studies; LNCS 1806; 2000; pp. 129-141

[DLT87] Daft, R.L.; Lengel, R.H.; Trevino, L.K. (1987): Message Equivocality, Media Selection and Manager Performance - Implications for Information Systems; in: MIS Quarterly; December 1999; pp. 355-368

[Ert99] Ertel, D.: Turning Negotiating into a Corporate Capability; in: Harvard Business Revue; May-June 1999; p. 55- 70

[FKH00] Friedman, P.; Kahn, P.H.; Howe, DC.: Trust Online; in: Communications of the ACM; December 2000; pp. 34-40

[Gen87] Genrich, H.J.: Predicate/transion nets; in: Brauer, W.; Reisig, W.; Rozenberg, G. (eds.); Petri Nets - Central Models and Their Properties; Advances in Petri Nets 1986; LNCS 254; 1987; pp. 207-247

[GSS00] Greunz, M.; Stanoevska-Slabeva, K.; Schopp, B.: Electronic Contracting with XML Containers; in: Jasper, H.; Küng, J.; Vossen, G. (eds.); Informationssysteme für ECommerce, Linz; 2000; p. 11-27

[HaB97] Hardwick, M.; Bolton, R.: The Industrial Virtual Enterprise; in: Communications of the ACM; Vol. 40; 1997; pp. 59-60 
[HeW00] Heuvel Van den, W.J.; Weigand, H.: Cross Organizational Workflow Integration Using Contracts; http://www.jeffsutherland.org/oopsla2000/ vandenheuvel/vandenheuvel.htm; (2000-12-20)

[IsM00] Ishaya T.; Macaulasy, L.: The Role of Trust in Virtual Teams; in: Sieber, P.; Griese, J. (eds.): Organization Virtualness and Electronic Commerce; (www.virtualorganization.net); (2000-07-17)

[KaJ99] Karahannas, M.; Jones, M.; Interorganizational Systems and Trust in Strategic Alliances; in: Hansen, H.R.; Bichler, M.; Mahrer, H. (eds.); Proc. 8th European Conference in Information Systems, Austria, July 2000; pp. 346-357

[LeO01] Lenz, K.; Oberweis, A.: Modeling Interorganizational Workflows with XML nets; in Proc. Thirty-Fourth Hawaii International Conference on System Sciences (HICSS-34), Januar 2001

[Lew99] Lewis, J.D.: Trusted Partners - How Companies Build Mutual Trust and Win Together; New York; 1999

[Lib89] Libecap, G.D.: Contracting for Property Rights; Cambridge; 1989

[Luh88] Luhmann, N.: Familiarity, Confidence, Trust - Problems and Alternatives; in: Gambetta, D. (eds.); Trust - Making and Breaking Cooperative Relations; Oxford; 1988

[Mac74] Macneil, I.R.: The Many Futures of Contracts; in: Southern California Review; Vol. 47; 1974; pp. 691-816

[MiF98] Millmann, R.E.; Fugate, D.I.: Using Trust-Transference as a Persuasion Technique; an Empirical Field Investigation; in: Journal of Personal Selling and Sales Management; 08/1998; p. 56-57

[MWK96] Meyerson, M.; Weick, K.E.; Kramer, R..M.: Swift Trust and Temporary Groups; in Kramer, R..M; Tyler, T.R..: Trust in Organizations; London; 1996; pp. 166-195

[ObS96] Oberweis, A.; Sander, P.: Information System Behavior Specification by HighLevel Petri Nets; in: ACM Transactions on Information Systems, 14(4); 1996; pp. 380-420

[Pet81] Peterson, J.L.: Petri Net Theory and the Modeling of Systems, Englewood Cliffs, 1981

[SaV99] Shapiro, C.; Varian, H.R.: Information Rules - a Strategic Guide to the Network Economy; Boston; 1999

[Shn00] Shneiderman, B.: Designing Trust into Online Experiences; in: Communications of the ACM; 12/2000; pp. 57-59

[SWC76]Short, J.W.; Williams, E; Christie, B.: The Social Psychology of Telecommunications; New York, 1976

[SWZ99] Sulin, B.; Whinston, A.; Zhang H.: Building Trust in the Electronic Market Through an Economic Incentive Mechanism; in: Prabudda, D.; DeGross; (eds.); Proceedings of the 20th International Conference on Information Systems; December 1999; pp. 208-213

[W3C00] World Wide Web Consortium Recommendation: Extensible Markup Language (XML) 1.0; Technical Report; 6-October-2000; (http://www.w3/TR/2000/REC-xml20000106)

[Zuc86] Zucker, L.G.: Production of Trust - Institutional Sources of Economic Structure; in: Research on Organizational Behavior; Vol. 8; 1986; pp. 53-111 